\title{
Urinary Cadmium and Blood Pressure: Results from the NHANES II Survey
}

\section{by Alice S. Whittemore,* Yasamin DiCiccio,* and George Provenzano ${ }^{\dagger}$}

\begin{abstract}
Relationships between urinary cadmium levels and blood pressure were examined in a sample of 951 adult men and women who participated in the Second National Health and Nutritional Examination Survey (NHANES II). Among all participants, positive relationships were seen between urinary cadmium levels and both systolic and diastolic blood pressure $(p<0.05$ and $p<0.01$, respectively), after adjusting for age, sex, race, relative body weight, smoking status, and hypertensive medication use. However, analyses for subgroups determined by sex and smoking status were inconsistent. Among current smokers, urinary cadmium levels were significantly positively associated with both systolic and diastolic blood pressure for women, and with diastolic blood pressure for men. Yet among former smokers and lifelong nonsmokers of both sexes, urinary cadmium was not significantly associated with either systolic or diastolic blood pressure. Evidence that some hypertensive medications increase urinary cadmium excretion suggests that the positive associations seen among current smokers may reflect high urinary cadmium levels among hypertensives induced by hypertensive treatment. After treated hypertensives were removed from the analysis, regression coefficients relating blood pressure to cadmium dropped by a factor of two and lost statistical significance. We conclude that the present data provide little support for a causal association between systemic cadmium and hypertension at nonoccupational exposure levels. Further, conflicting results of previous studies may reflect failure to control adequately for age, smoking status, and hypertensive treatment.
\end{abstract}

\section{Introduction}

Animal studies of long-term cadmium exposures (1-6) and occupational studies (7) suggest that exposure to high cadmium levels may increase blood pressure. However, effects of exposures to lower cadmium levels that are typical of nonoccupationally exposed populations are unclear, with some studies showing a positive association (8-12) and others showing no association $(13,14)$ or even a negative association $(15,16)$. The potential for increased exposure to cadmium as an environmental contaminant, coupled with the element's tendency to accumulate in the body, has raised concern that exposures to current environmental levels may themselves contribute to hypertension in the general population (17). Cadmium from the soil tends to accumulate in many vegetable crops, so that increased application of municipal sludge to agricultural land may cause increased cadmium exposure through food ingestion $(18,19)$.

\footnotetext{
*Stanford University School of Medicine, Department of Health Research and Policy, Stanford, CA 94305.

†University of Maryland School of Medicine, Department of Epidemiology and Preventive Medicine, Baltimore, MD 21201.

Address reprint requests to A. S. Whittemore, Stanford University School of Medicine, Department of Health Research and Policy, HRP Building, Room 113, Stanford, CA 94305.
}

Here we report relationships between blood pressure and urinary cadmium in a multistage stratified probability sample of approximately 1000 adult men and women from the central and eastern United States. These individuals compose a subsample of the second U.S. National Health and Nutritional Examination Survey (NHANES II), conducted during the period 1976 to $1988(20)$.

\section{Methods}

\section{Subjects}

The NHANES II survey assessed health status of individuals from 64 areas [called primary sampling units (PSUs)] selected from a stratified sample of 1924 geographic areas within the United States. These areas, which typically consist of one or more contiguous counties, were stratified according to region, racial composition, and degree of urbanization (20). Within each of these 64 PSUs, a nested sampling design selected census enumeration districts, housing clusters within districts, households within housing clusters, and respondents within households. This design achieved 20,325 responses from a survey of 27,803 noninstitutionalized civilians aged 6 months to 74 years. The data include responses to direct medical examination, medical history, 24-hr dietary recall, 
health-related behavior, and demographic questions. Systolic and diastolic blood pressure were measured three times during the examination; at the beginning with the subject in a sitting position; and at the end, in both sitting and reclining positions. Procedures were based on guidelines published by the American Heart Association (21). Further details on the design of this survey can be found elsewhere $(20,22)$.

As part of a collaboration between the National Center for Health Statistics (NCHS) and the U.S. Environmental Protection Agency (EPA), NHANES II personnel collected and aliquoted for cadmium analysis a single casual urine specimen from a subsample of approximately 1000 study subjects during 1978-1979. (Urinary cadmium is regarded as a measure of longterm accumulation of this element.) Subjects in the subsample were of both sexes, 20 to 74 years of age, and from selected PSUs in nine states (Arkansas, Illinois, Indiana, Michigan, New Jersey, New York, Ohio, Pennsylvania, and Texas). Subjects were chosen to represent the general adult United States population, stratified by age, sex, and income level.

\section{Urine Analysis}

Urine samples were frozen with dry ice within $1 \mathrm{hr}$ of collection and were shipped frozen to a clinical laboratory (Swedish Hospital Medical Center, Seattle, WA), where they were analyzed for cadmium, $\beta_{2}$-microglobulin, specific gravity, and creatinine.

Cadmium analysis was performed by chelation and extraction. A 1 -mL portion of $2 \%$ sodium $N, N$-diethyldithiocarbamate was mixed with $5 \mathrm{~mL}$ urine in a centrifuge tube. Methyl isobutyl ketone ( $3 \mathrm{~mL}$ ) was added, and the tube was mixed, centrifuged for $5 \mathrm{~min}$, and separated. The organic phase was then analyzed for cadmium by flameless atomic absorption spectrometry, using a Perkin-Elmer 306 instrument with an HGA-2100 graphite furnace. A calibration curve was made from spiked composite urine. Analysis was done in duplicate, with controls in each run, and accuracy of calibration was assessed using National Bureau of Standards standard reference material SRM 1643.

Adjustment for urine concentration is needed because subjects provided single (rather than 24-hr) urine samples. We adjusted the cadmium levels to a specific gravity of 1.020 as follows: adjusted cadmium level $=0.020 \times$ sample urinary cadmium level/(sample specific gravity - 1.000). Specific gravity was measured by refractometer.

\section{Statistical Analysis}

Multiple linear regression was used to examine relationships of urinary cadmium to systolic and diastolic blood pressure (arithmetic mean of the three measurements taken at interview), adjusted for age, race, relative body weight, cigarette smoking status, and current hypertensive medication use. Multiple logistic regression was used to examine relationships of uri- nary cadmium to current hypertensive medication use, adjusted for age, race, weight, and smoking status. Regressions were performed using both urinary cadmium and its natural logarithm. Results were similar for the two analyses, so we report only those based on the untransformed cadmium values.

The design used to subsample subjects for cadmium analysis precludes variance estimation for regression coefficients using Taylor series approximations or balanced-half sample methods $(23,24)$ that accommodate the clustered nature of the survey. Furthermore, sampling weights appropriate for subjects in the cadmium subsample were not available. Therefore, all $p$ values and confidence limits are based on the assumption that the cadmium subsample is a simple random sample of the adult U.S. population.

\section{Results}

Blood pressure and urinary cadmium levels were available for a total of 960 subjects. Of these, four were excluded because their cadmium levels exceeded 20 $\mu \mathrm{g} / \mathrm{L}$ [considered an upper bound for plausible values in environmentally exposed individuals (17)], and five were excluded because their smoking status was unknown. Table 1 shows summary descriptive statistics for the remaining 951 subjects. A higher fraction of women than men were nonwhite, used hypertensive medication, and had avoided the cigarette habit. Women also had higher urinary cadmium levels than did men.

Figure 1 shows strong age-related increases in mean urinary cadmium levels up to age 70 years for both men and women. An increasing trend of urinary cadmium with age has been noted in several studies $(25,26)$ and may reflect the increasing body burden of cadmium with age. Figure 1 also shows a drop in cadmium among both men $(n=45)$ and women $(n=39)$ aged 70 to 74 years.

Table 1. Mean characteristics of study subjects. ${ }^{a}$

\begin{tabular}{lcr}
\hline Characteristic & Men & Women \\
\hline Number & 474 & \multicolumn{1}{c}{477} \\
Age, years & $46.9 \pm 0.8$ & $47.3 \pm 0.8$ \\
Race, \% & & \\
$\quad$ White & $90.5 \pm 1.3$ & $85.7 \pm 1.6$ \\
$\quad$ Black & $0.6 \pm 1.3$ & $13.2 \pm 1.5$ \\
$\quad$ Other & & $1.1 \pm 0.5$ \\
Blood pressure & $131.7 \pm 0.9$ & $129.0 \pm 1.1$ \\
$\quad$ Systolic, mm Hg & $81.4 \pm 0.5$ & $79.0 \pm 0.6$ \\
$\quad$ Diastolic, mm Hg & $42.4 \pm 2.3$ & $45.3 \pm 2.3$ \\
Family history of hypertension, \% & \\
Hypertensive medication use, \% & $11.2 \pm 0.02$ & $15.3 \pm 0.2$ \\
Quetelet's index of relative & & \\
$\quad$ body weight, kg/m & \\
Cigarette smoking status, \% & $25.6 \pm 0.2$ & $25.7 \pm 0.3$ \\
$\quad$ Current smokers & $35.2 \pm 0.05$ & $27.9 \pm 0.04$ \\
$\quad$ Former smokers & $34.4 \pm 0.05$ & $15.7 \pm 0.03$ \\
$\quad$ Lifelong nonsmokers & $30.4 \pm 0.05$ & $56.4 \pm 0.05$ \\
Urinary cadmium, $\mu$ g/L & $1.1 \pm 0.04$ & $1.3 \pm 0.07$ \\
\hline
\end{tabular}

${ }^{a}$ Values presented as means \pm standard error.

${ }^{b}$ Parents or siblings.

'Quetelet's index = weight $/$ height ${ }^{2}$. 


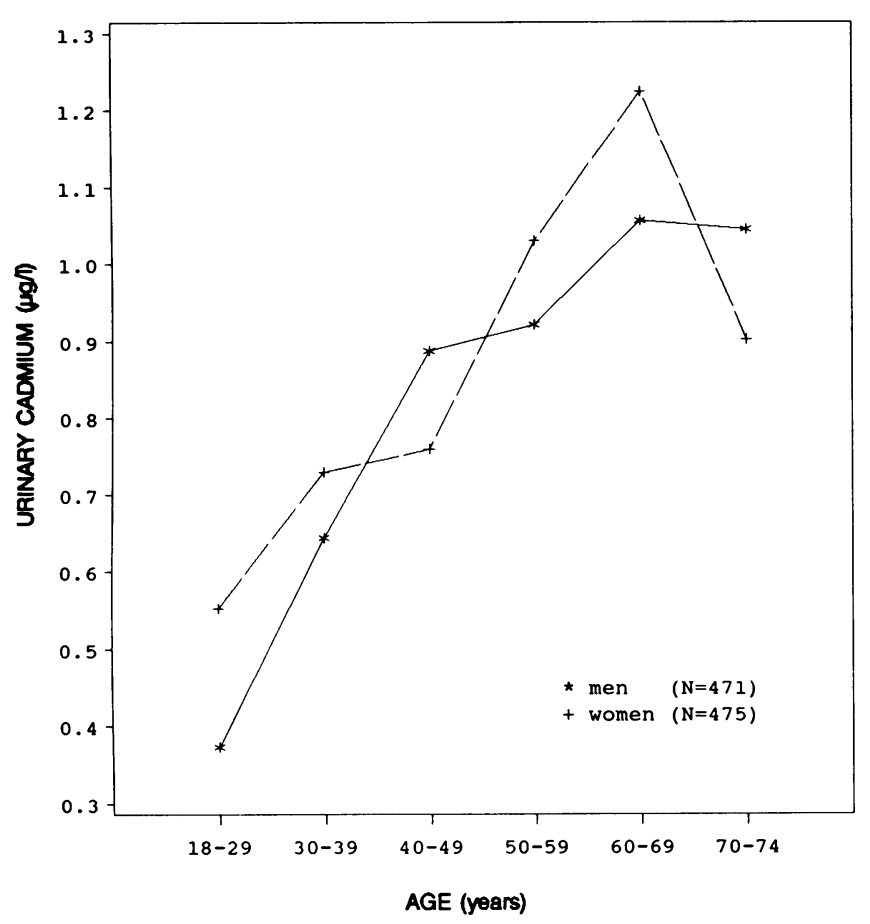

FIGURE 1. Geometric means of specific-gravity-adjusted urinary cadmium levels versus age.

Cigarettes contain high concentrations of cadmium (0.5-2.0 $\mu \mathrm{g} /$ cigarette) $(17,27)$. Moreover, inhaled cadmium is absorbed more readily than ingested cadmium (27). Therefore, cigarette smoking is an important source of exposure to cadmium. Figure 2 shows that cadmium levels increase with cigarette smoking rate among current smokers $(p<0.001)$. The slope of the fitted least squares regression line was not affected by adjustment for age.

We next investigate associations between urinary cadmium and blood pressure. Table 2 presents multiple regression coefficients for blood pressure (systolic and diastolic) in relation to selected characteristics, among all participants combined. Both measures of blood pressure increased nonlinearly with age and increased linearly with Quetelet's index of relative body weight (weight in kilograms divided by the square of height in meters). By contrast, no significant or consistent effects were seen for sex, race (black vs. nonblack), or cigarette smoking status. (The number of blacks in the group was too small to provide a sensitive assessment of racial differences in hypertension). The coefficients for hypertensive medication use indicate that users had higher diastolic pressures and considerably higher systolic pressures than did nonusers.

Table 2 shows that urinary cadmium levels were significantly and positively related to both systolic $(p<$ $0.05)$ and diastolic $(p<0.01)$ pressure, after adjustment for the other variables in the table. We added powers of urinary cadmium levels to the regressions,

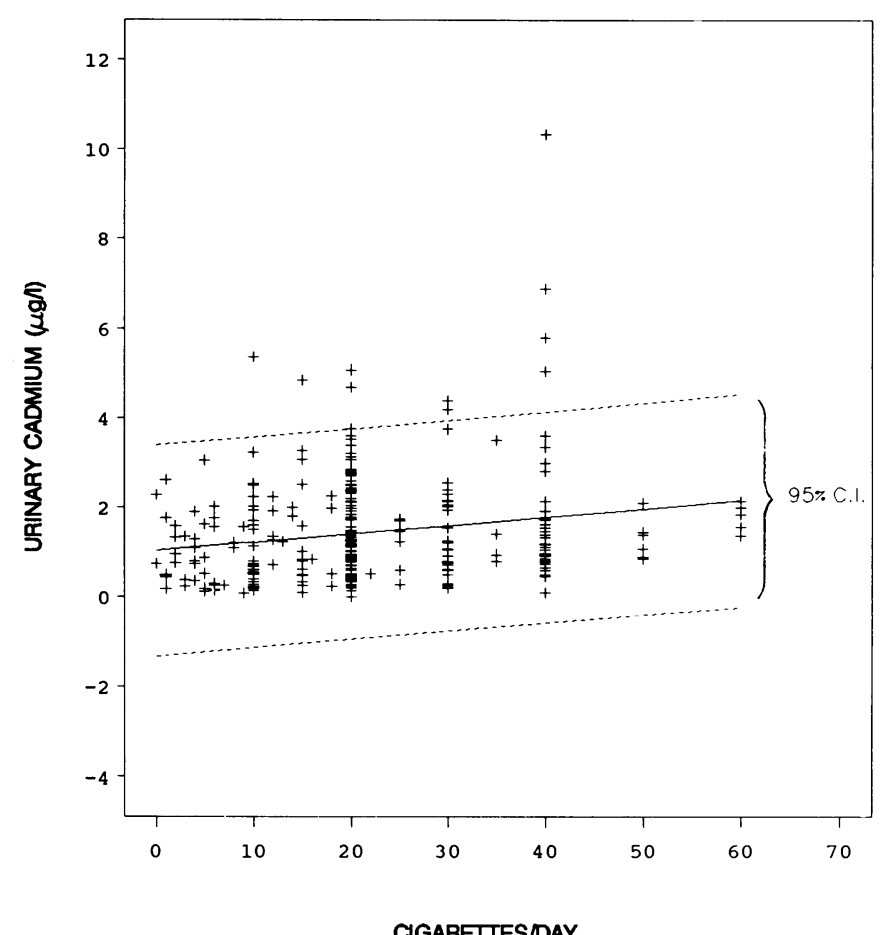

FIGURE 2. Urinary cadmium level versus current cigarette smoking rate among men and women. Fitted line has slope 0.02 (standard error $=0.01)$ and intercept $1.03(0.14)$.

Table 2. Multiple regression coefficients for three measures of hypertension in relation to selected characteristics among 951 participants.

\begin{tabular}{|c|c|c|c|c|c|c|}
\hline \multirow[b]{2}{*}{ Characteristic } & \multicolumn{4}{|c|}{ Blood pressure, $\mathrm{mm} \mathrm{Hg}$} & \multirow{2}{*}{\multicolumn{2}{|c|}{$\begin{array}{l}\text { Hypertensive } \\
\text { medication use }\end{array}$}} \\
\hline & \multicolumn{2}{|c|}{ Systolic } & \multicolumn{2}{|c|}{ Diastolic } & & \\
\hline Number & \multicolumn{2}{|c|}{951} & \multicolumn{2}{|c|}{951} & \multicolumn{2}{|c|}{951} \\
\hline Age, years & 0.23 & $(0.24)^{\mathrm{a}}$ & 0.77 & $(0.15)$ & 0.29 & $(0.09)$ \\
\hline $\mathrm{Age}^{2} \times 10$ & 0.07 & $(0.03)$ & -0.07 & $(0.02)$ & -0.02 & $(0.01)$ \\
\hline Gender, female & -4.08 & (1. & -3.23 & $(0.70)$ & 0.28 & $(0.24)$ \\
\hline Race, black & 0.05 & $(1.83)$ & -0.78 & (1.08) & 0.07 & $(0.35)$ \\
\hline $\begin{array}{l}\text { Quetelet's index, } \\
\mathrm{km} / \mathrm{m}^{2} \\
\text { Cigarette smoking }\end{array}$ & 1.37 & $(0.12)$ & 0.89 & $(0.07)$ & 0.09 & 2) \\
\hline Forn & $\begin{array}{l}-2.49 \\
-0.41\end{array}$ & $\begin{array}{l}(1.50) \\
(1.38)\end{array}$ & $\begin{array}{l}-0.83 \\
-0.63\end{array}$ & $\begin{array}{l}(0.89) \\
(0.82)\end{array}$ & $\begin{array}{r}0.01 \\
-0.48\end{array}$ & $\begin{array}{l}(0.26) \\
(0.31)\end{array}$ \\
\hline $\begin{array}{l}\text { Family history of } \\
\text { hypertension }\end{array}$ & 2.96 & (1.16) & 1.96 & $(0.69)$ & 1.24 & $(0.22)$ \\
\hline $\begin{array}{l}\text { Hypertensive } \\
\text { medication use } \\
\text { Urinary cadmium }\end{array}$ & 11.35 & $(1.81)$ & 3.68 & (1.08) & - & - \\
\hline$\mu \mathrm{g} / \mathrm{L}$ & 1.16 & $(0.49)$ & 0.84 & $(0.29)$ & -0.06 & $(0.09)$ \\
\hline
\end{tabular}

${ }^{\mathrm{a}}$ Standard errors in parentheses.

but found no evidence of nonlinearity in the relationship. The cadmium coefficients and their $95 \%$ confidence limits are shown in Figure $3 A$ and $C$. The figure 3 also shows point estimates and $95 \%$ confidence intervals for regression coefficients relating blood pressure to urinary cadmium levels separately by sex and smoking status (adjusted for age, race, Quetelet's index, and current hypertensive medication use). These subgroupspecific regression coefficients are not consistent. 

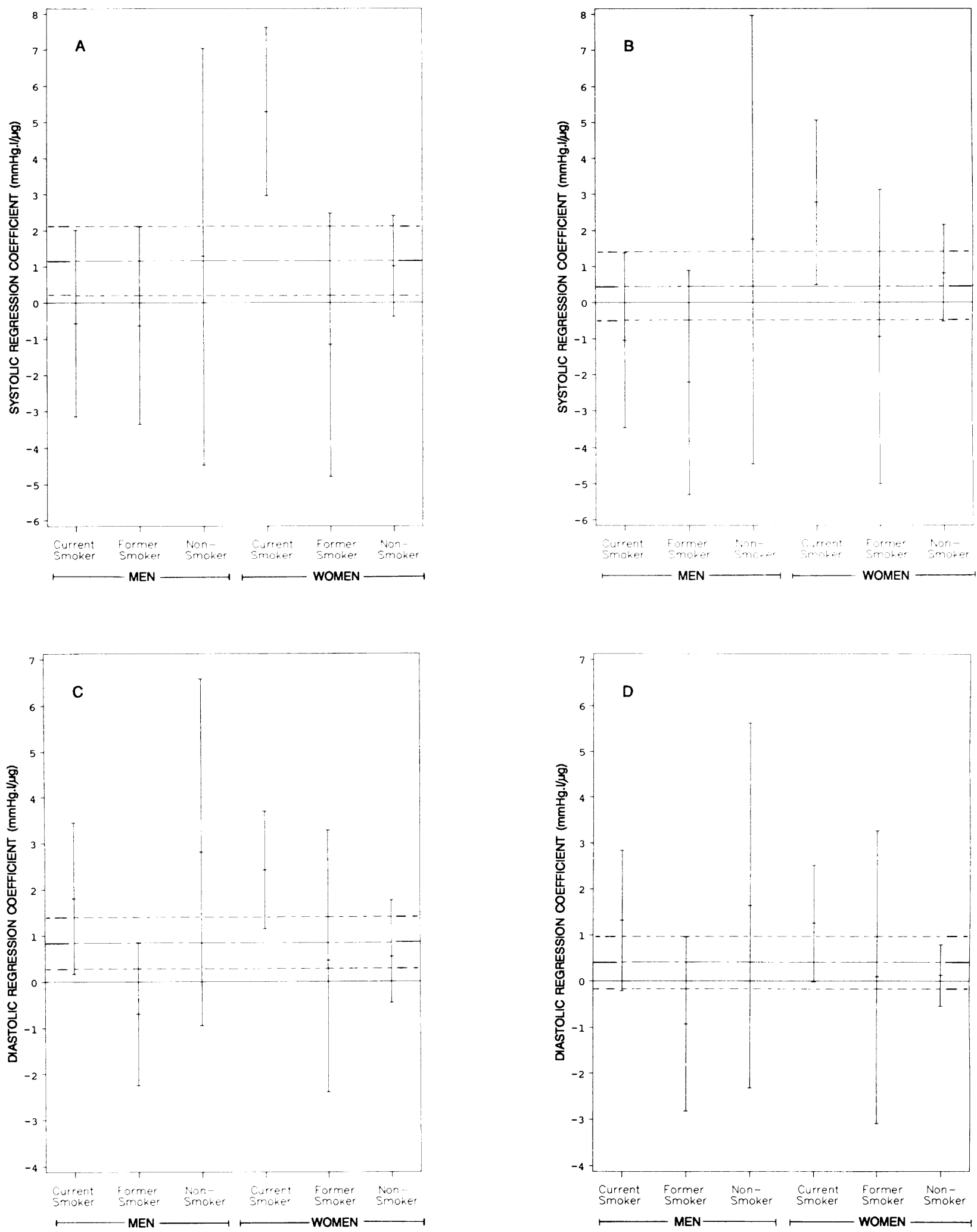

FIGURE 3. Estimated regression coefficients and $95 \%$ confidence intervals for systolic $(A, C)$ and diastolic $(B, D)$ blood pressure versus urinary cadmium level by sex and smoking status. All coefficients adjusted for age, age ${ }^{2}$, race (black, nonblack), Quetelet's index of relative body weight, and family history of hypertension. Dashed lines indicate overall coefficients, adjusted also for sex and smoking status, and $95 \%$ confidence intervals. $(A, C)$ Include all subjects and are adjusted for current hypertensive medication use (yes, no). (B,D) Exclude treated hypertensives. 
Among men, the coefficient is significantly positive only for diastolic pressure in current smokers. Among women, significantly positive coefficients are seen for both systolic and diastolic pressure in current smokers, but not for any other comparison.

The positive regression coefficients seen among current smokers might reflect a direct association between blood pressure and smoking rate. However, in agreement with other findings $(28,29)$ we found no associations between systolic or diastolic blood pressure and reported smoking rate in cigarettes per day among current smokers, after adjustment for the other variables in Table 2 . Moreover, the significantly positive regression coefficients noted for urinary cadmium among current smokers persisted after controlling for smoking rate.

Some hypertensive treatments appear to increase the excretion of renal cadmium. For example, Wester (30) noted increased urinary cadmium concentration in hypertensives following treatment with chlorthalidone, and McKenzie and Kay (31) reported greater 24 $\mathrm{hr}$ urinary concentration of cadmium in treated hypertensive women compared with a normotensive group. Therefore, the positive associations seen in Figure 3 might reflect merely iatrogenically elevated urinary cadmium levels among treated hypertensives. This possibility is investigated in Figure $3 B$ and $D$, which show regression coefficients relating blood pressure to urinary cadmium levels when individuals who reported using hypertensive medications were deleted from the analyses. Comparisons with Figure $3 A$ and $C$ reveal substantial decreases in the regression coefficients for both systolic and diastolic blood pressure. All coefficients are reduced by a factor of two. Only the coefficient for systolic pressure in currently smoking women remains statistically significant.

Figure 4 shows scatter plots of blood pressure versus cadmium among current smokers, with those taking hypertensive medication distinguished from other participants. Also shown are nonparametric regression curves for each of the two types of data (32). The graph shows several outlying subjects on hypertensive medication who have high levels of both cadmium and blood pressure. These individuals have a disproportionate effect on estimated regression coefficients relating cadmium to blood pressure. The large regression coefficient reductions occasioned by their removal suggests that the positive associations between cadmium and hypertension noted here do not reflect a causal mechanism, but rather an effect of hypertensive treatment.

Table 2 presents multiple logistic regression coefficients relating current hypertensive medication use to demographic characteristics, body size, smoking status, and urinary cadmium. Hypertensive medication users were older and heavier for their height than were nonusers. However, the two groups did not differ significantly with respect to sex, race, or smoking status. The groups also were similar with respect to urinary cadmium levels $(p=0.50)$, despite the presence of outlying users with high cadmium levels seen in Figure 4.
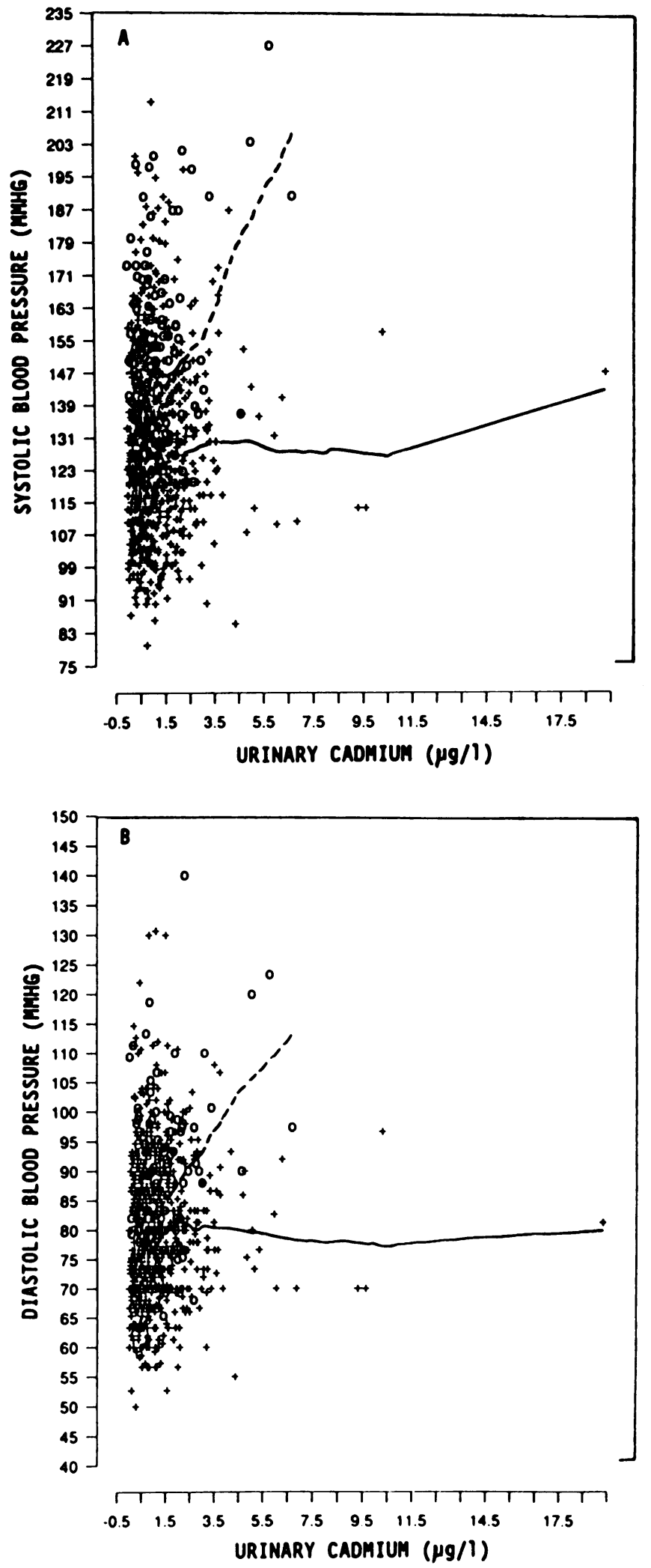

FiguRE 4. Scatter plot and nonparametric regression curves (32) for $(A)$ diastolic and $(B)$ systolic blood pressure versus urinary cadmium among current smokers who use $(0,--)$ and do not use $(+,-)$ hypertensive medication. 
This apparent inconsistency is probably due to robustness of the logistic coefficient estimates against occasional high, outlying cadmium levels among users. Such robustness contrasts with the observed lack of robustness of the ordinary least squares estimates relating blood pressure levels to urinary cadmium.

All of the regression coefficients relating cadmium to hypertension remained essentially unchanged when years of education and blood lead levels were included in the regressions. Since blood lead levels were unavailable for half the participants, inclusion of this variable in the regressions reduced the sample size by half. Thus we have not presented results of regressions that include blood lead levels.

\section{Discussion}

Using data from 951 participants in the NHANES II Survey, we have examined variation of urinary cadmium levels with age, sex, and smoking status, and associations between urinary cadmium levels and blood pressure levels. Cadmium levels increased with age and, among smokers, with smoking rate. The positive associations seen between urinary cadmium and age are consistent with other findings $(18,25)$. Cadmium levels found in the kidney and liver at autopsy increase with age (33). with the kidney containing about onethird of the total body burden (17). Similarly, the positive association seen between urinary cadmium and reported cigarette smoking rates among current smokers is consistent with other observations $(25,26,34,35)$. The drop in cadmium levels seen in Figure 1 among older individuals could be related to an age-related decline in glomerular filtration rate.

Among all participants, statistically significant positive relationships were seen between urinary cadmium levels and both systolic and diastolic blood pressure, after adjusting for age, sex, race, relative body weight, smoking status, and hypertensive medication use. However, analyses by subgroups determined by sex and smoking status were inconsistent. Among current smokers, urinary cadmium levels were positively associated with both systolic and diastolic blood pressure for women, and with diastolic blood pressure for men. Yet among former smokers and lifelong nonsmokers of both sexes, urinary cadmium was unrelated to either systolic or diastolic blood pressure. Further, when treated hypertensives were removed from analysis, regression coefficients decreased and lost statistical significance.

Several study limitations must be considered in interpreting the results. First, we cannot exclude the possibility that relationships of cadmium to blood pressure differed between survey respondents and nonrespondents. (The overall response rate for the NHANES II survey was $73 \%$.) Second, the cadmium levels are subject to measurement error. Cadmium measurements were based on a single casual urine specimen taken at examination; therefore, it was necessary to adjust the cadmium levels for variable urine concen- trations. The sampling procedure and the adjustment are sources of measurement error. Moreover, day-today variation in cadmium concentration has been demonstrated in complete 24 -hr specimens (36). The multiple regression analysis used here does not accommodate such intrasubject variation in measured urine cadmium concentrations. Lack of information on the extent of such variation precludes an analysis that accommodates measurement error for cadmium. In the presence of such error, ordinary multiple regression analysis produces coefficients for cadmium that are biased toward zero (37).

Third, we estimated standard errors for the regression coefficients under the assumption of simple random sampling, with each participant having equal probability of being sampled. The clustered nature of the NHANES sampling design introduces correlation between variables measured on subjects within the same PSU. Positive correlation can bias variance estimates downward, thereby exaggerating significance levels. Although empirical and theoretical studies have shown that the bias in variances of regression coefficients is likely to be small, its effect in this study is unknown. The limited number of PSUs used to select subjects for cadmium analysis has precluded the use of methods $(23,24)$ to obtain unbiased variance estimates. (We repeated the blood pressure regressions using a model with subjects' PSUs taken as random effects and all other independent variables taken as fixed effects. Such a model allows positive covariance between blood pressure measurements for subjects within the same PSU, but it assumes unrealistically that the covariance is constant across all pairs of subjects and across all PSUs. As expected, variances of the estimated cadmium coefficients increased in this model, and the estimates lost statistical significance.)

Despite the aforementioned limitations, the positive associations seen between cadmium and blood pressure among current smokers require interpretation. Concern about a possible causal effect of cadmium on hypertension arises because cadmium accumulates in the renal cortex (17) and has been associated with renal damage (38-40). Cadmium-induced renal damage has been conjectured to cause hypertension by increasing the retention of salts and water and/or the production of angiotensin, a powerful vasoconstrictor. Yet few biological explanations come to mind for a causal association between cadmium and hypertension that is limited to current smokers. Confounding by hypertensive treatment is a more likely explanation for the present findings, because the subgroup of current smokers included treated hypertensives with very high levels of both cadmium and blood pressure. These individuals greatly influenced the estimated regression coefficients, even in analyses that stratified on medication use. Indeed, little evidence for an association persisted after their removal from the analysis. The possible causal pathway from hypertensive treatment to elevated urinary cadmium levels illustrates the difficulties of causal inference from cross-sectional data. 
Other epidemiologic data relating systemic cadmium levels to hypertension also are conflicting. Some studies have found higher blood cadmium levels in hypertensive than in normotensive adults $(9,11,12)$, while others have found no differences (41). The positive findings are difficult to interpret because the comparisons were not controlled for differences in age and smoking status between hypertensives and normotensives. Similarly, no clear picture has emerged from comparisons between hypertensives and normotensives in renal cadmium concentrations measured either at autopsy $(8,10,15)$ or in vivo $(13)$. Failure to control for age and smoking status also complicates these comparisons. It is noteworthy that a slight negative association between urinary cadmium levels and blood pressure was found in a population-based Belgian study (16) which, like the present one, excluded treated hypertensives and controlled for age, smoking status, and obesity.

In summary, existing data do not support a causal relationship between cadmium exposure and elevated blood pressure among adults who are not occupationally exposed to cadmium or treated for hypertension. Elucidation of such a potential causal relationship requires further research incorporating control for the potential confounding effects of age, cigarette smoking, and hypertensive medication use. The Third National Health and Nutrition Examination Survey, conducted during the period 1988 to 1994 , will include cadmium analysis of urine samples for approximately 30,000 adult participants. These data will be useful in resolving the issues raised here.

This research was supported by a grant to SIMS from the U.S. Environmental Protection Agency.

\section{REFERENCES}

1. Perry, H. M., and Erlanger, M. W. Metal-induced hypertension following chronic feeding of low doses of cadmium and mercury. J. Lab. Clin. Med. 83: 541-547 (1974).

2. Perry, H. M., Erlanger, M., and Perry, E. F. Hypertension following chronic, very low dose cadmium feeding. Proc. Soc. Exp. Biol. Med. 156: 173-176 (1977).

3. Perry, H. M., Erlanger, M. W., and Perry, E. F. Elevated systolic pressure following chronic low-level cadmium feeding. Am. J. Physiol. 232: H114-H121 (1977).

4. Perry, H. M., Erlanger, M., and Perry, E. F. Increase in the systolic pressure of rats chronically fed cadmium. Environ. Health Perspect. 28: 251-260 (1979).

5. Schroeder, H. A., and Vinton, W. H. Hypertension induced in rats by small doses of cadmium. Am. J. Physiol. 202: 515-518 (1962).

6. Schroeder, H. A. Cadmium hypertension in rats. Am. J. Physiol. 207: 62-66 (1964).

7. Thun, M. J., Osorio, A. M., Schober, S., Hannon, W. H., and Halperin, W. Nephropathy in cadmium workers-assessment of risk from airborne occupational cadmium exposure. Br. J. Ind. Med. 46: 689-697 (1989).

8. Lener, J., and Bibr, B. Cadmium and hypertension. Lancet i: 970 (1971).

9. Thind, G. S., and Fischer, G. M. Plasma cadmium and zinc in human hypertensives. Clin. Sci. Mol. Med. 51: 483-486 (1976).

10. Schroeder, H. A. Cadmium as a factor in hypertension. J. Chron. Dis. 18: 647-656 (1965).
11. Revis, N. W., and Zinsmeister, A. R. The relationship of blood cadmium level to hypertension and plasma norepinephrine level: a Romanian study. Proc. Soc. Exp. Biol. Med. 167: 254-260 (1981).

12. Glauser, S. C., Bello, C. T., and Glauser, E. M. Blood-cadmium levels in normotensive and untreated hypertensive humans. Lancet i: 717-718 (1976).

13. Cummins, P. E., Dutton, J., Evans, C. J., Morgan, W. D., Sivyer, A., and Elwood, P. C. An in vivo study of renal cadmium and hypertension. Eur. J. Clin. Invest. 10: 459-461 (1980).

14. Beevers, D. G., Campbell, B. C., Goldberg, A., and Moore, M. R. Blood-cadmium in hypertensives and normotensives. Lancet ii: 1222-1224 (1976).

15. Ostergaard, K. Cadmium and hypertension. Lancet i: 677-678 (1977).

16. Staessen, J., Bulpitt, C. J., Roels, H., Bernard, A., Fagard, R., Joosens, J. V., Lauwerys, R., Lijnen, P., and Amery, A. Urinary cadmium and lead concentrations and their relation to blood pressure in a population with low exposure. Br. J. Ind. Med. 41: 241-248 (1984).

17. Friberg, L., Piscator, M., Nordberg, G., and Kjellström, T. Cadmium in the Environment, 2nd ed. CRC Press, Boca Raton, FL, 1974.

18. Kowal, N. E., and Zirkes, M. Urinary cadmium and beta ${ }_{2}-\mathrm{mi}$ croglobulin: normal values and concentration adjustment. J. Toxicol. Environ. Health 11: 607-624 (1983).

19. Jelinek, C. F., and Braude, G. L. Management of the sludge use on land, FDA considerations. In: Proceedings of the Third National Conference on Sludge Management, Disposal and Utilization. Information Transfer, Inc., Rockville, MD, 1977, pp. 35-38.

20. National Health and Nutrition Examination Survey 1976-1980 (NHANES II). U.S. Department of Health and Human Services, National Center for Health Statistics, Hyattsville, MD, 1982.

21. American Heart Association's Recommendations for Human Blood Pressure Determinations by Sphygmomanometers (Com. mittee to Revise Standardization of High Blood Pressure Readings) American Heart Association, New York, October, 1951.

22. Landis, J. R., Lepowski, J. M., Eklund, S. A., and Stenhouwer, S. A. A Statistical Methodology for Analyzing Data from a Complex Survey: The First National Health and Nutrition Survey. Vital and Health Statistics 1982, Series 2, No. 92. DHHS Pub. No. (PHS) 82-1336. U. S. Government Printing Office, Washington, DC, 1982.

23. Wolker, K. M. Introduction to Variance Estimation. Springer Verlag, New York, 1985.

24. EVCARP. Statistical Laboratory, Iowa State University, Ames, IA, 1987.

25. Kowal, N. E., Johnson, D. E., Kramer, D. F., and Pahren, D. F. K. Normal levels of cadmium in diet, urine, blood and tissues of inhabitants of the United States. J. Toxicol. Environ. Health 5: 995-1014 (1979).

26. Elinder, C. G., Kjellström, T., Linnman, L., and Pershagen, G. Urinary excretion of cadmium and zinc among persons from Sweden. Environ. Res. 15: 473-484 (1978).

27. Friberg, L., Elinder, C. G., Kjellstrom, T., and Nordberg, G. F. Cadmium and Health: A Toxicological and Epidemiological Appraisal, Vol. 1, Exposure, Dose, and Metabolism. CRC Press, Boca Raton, FL, 1985.

28. Ballantyne, D., Devine, B. L., and Fife, R. Interrelation of age, obesity, cigarette smoking, and blood pressure in hypertensive patients. Br. Med. J. 1: 880-881 (1978).

29. Greene, S. B., Avedal, M. D., Tyroler, H. A., Davis, C. E., and Hames, C. G. Smoking habits and blood pressure change: a seven-year follow-up. J. Chron. Dis. 30: 401-413 (1977).

30. Wester, P. O. Trace elements in serum and urine from hypertensive patients before and during treatment with chlorthalidone. Acta Med. Scand. 194: 505-512 (1973).

31. McKenzie, J. M., and Kay, D. L. Urinary excretion of cadmium, zinc, and copper in normotensive and hypertensive women. N. Zeal. Med. J. 78: 68-70 (1973).

32. Cleveland, W. S. Robust locally weighted regression and smoothing scatter plots. J. Am. Stat. Assoc. 74: 829-836 (1979).

33. Tipton, I.H. The distribution of trace metals in the human body. 
In: Metal-Binding in Medicine (M.J. Seven, Ed.), Proceedings of a Symposium Sponsored by Hahnemann Medical College and Hospital. J. B. Lippincott Co., Philadelphia, 1960, pp. 27-42.

34. Lewis, G. P., Jusko, W. J., Coughlin, L. L., and Hartz, S. Cadmium accumulation in man: influence of smoking, occupation, alcoholic habit and disease. J. Chron. Dis. 25: 717-726 (1972).

35. Kowal, N. E. Urinary cadmium and beta2-microglobulin correlation with nutrition and smoking history. J. Toxicol. Environ. Health 25: 179-183 (1988).

36. Tati, M., Katagiri, Y., and Kawai, M. Urinary and fecal excretion of cadmium in normal Japanese: an approach to non-toxic levels of cadmium. In: Effects and Dose-Response Relationships of Toxic Metals (G.F. Nordberg, Ed.), Elsevier Scientific Publishing Co., Amsterdam 1976, pp. 331-342.

37. Fuller, W. Measurement Error Models. John Wiley and Sons, New York, 1987.
38. Smith, T. J., Anderson, R. J., and Reading, J. C. Chronic cadmium exposures associated with kidney function effects. Am. J. Ind. Med. 1: 319-337 (1980).

39. Lauwerys, R. R., Buchet, J. P., Roels, H. A. Brouwers, J., and Stanescu, D. Epidemiological survey of workers exposed to cadmium. Arch. Environ. Health 28: 145-148 (1974).

40. Kjellström, T., Evrin, P. E., and Rahnster, B. Dose-response analysis of cadmium-induced tubular proteinuria. A study of urinary beta-2-microglobulin excretion among workers in a battery factory. Environ. Res. 13: 303-317 (1977).

41. Beevers, D. G., Cruickshank, J. K., Yeoman, W. B., Carter, G. F., Goldberg, A., and Moore, M. R. Blood-lead and cadmium in human hypertension. J. Environ. Pathol. Toxicol. 4: 251-260 (1980). 